Vol.15, No. 55, April, 2020, 672-684

\title{
JAUES
}

\section{IMPROVING CAR PARKING MANAGEMENT IN UNIVERSITY CITIES: THE CASE STUDY OF KING SAUD UNIVERSITY}

\author{
Abdulaziz Jarallah Al-Degheishm \\ Urban Planning Department, College of Architecture and Planning, King Saud University, \\ Al Riyadh, Saudi Arabia \\ E-mail: aldeghei@ksu.edu.sa
}

\begin{abstract}
This research aims to study how to provide and manage car parking at King Saud University by reviewing the basic principles of management, analysis of the current status of land use, attitudes, the volume of traffic, the characteristics of the campus university, and the need to provide parking management within the university city. It also describes the estimate supply and demand situations through field surveys that have been done for this study and take advantage of previous studies have been carried out in this field, where they were positioning quality, type and available from places stand in all of them have been identified demand for parking in terms of number of vehicles in each parking and the duration of stand compared to the absorptive capacity of the demand size. This research also reviews the critical issues facing the current situation of the parking and in the future, where demand is expected to expand the uses of land and the establishment of a number of future facilities. The study concludes in addressing the current situation of the parking and work to improve it through a number of policies which include the importance of providing the required number of parking for each new facilities and the provision of access to parking and improve communication between the plazas and buildings parking with the need to identify the parking to be used by specific groups and improve the design of plazas and provide a safe and comfortable pedestrian corridors. It also recommends research to follow policies designed to reduce the demand for attitudes and distributed geographically so can be used by other modes of transport such as public transport or walking and the use of intelligent transport systems that contribute to make the most of the parking lots available with enforcement of traffic violations for the misuse of parking and punish violators.
\end{abstract}

\section{KEYWORDS: Car Parking, University, University Cities, Traffic, Operation, Administration}

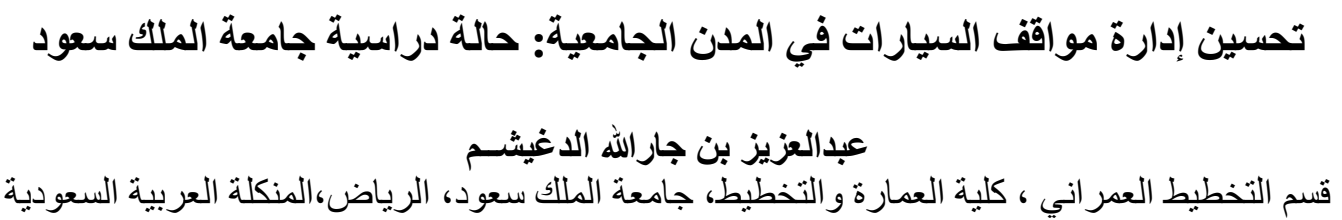

E-mail: aldeghei@ksu.edu.sa

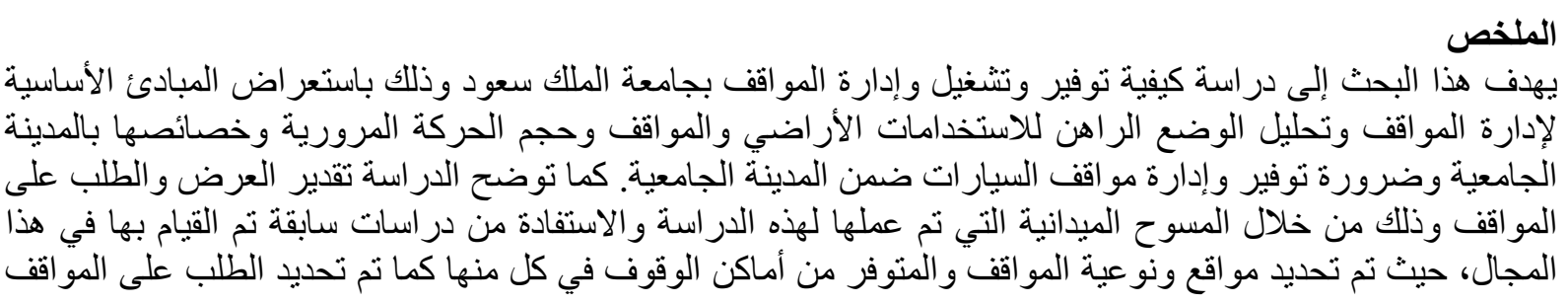




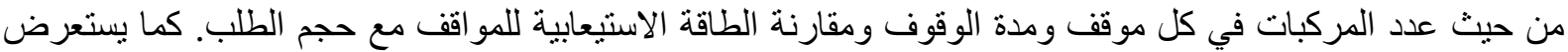

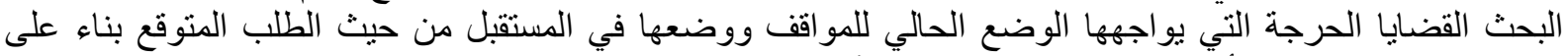

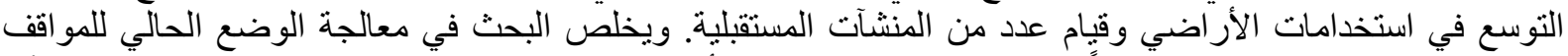

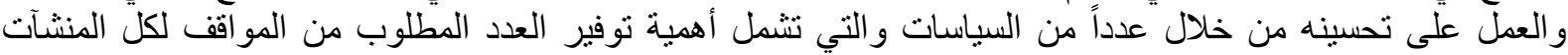

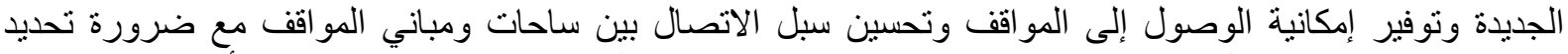

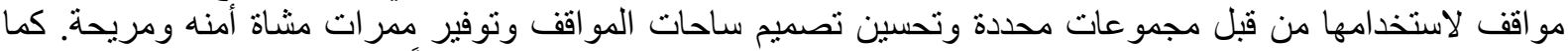

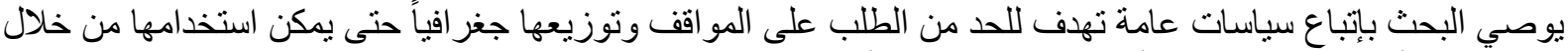

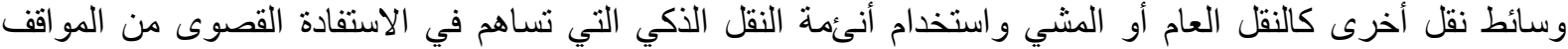
المتوفرة مع تطبيق المخالفات للاستخدام الخاطئ للمو اقف ومعاقبة المخالفين.

\section{الكلمات المفتاحية: مواقف السيارات، جامعة، المدن الجامعية، الحركة المرورية،، تشغيل، إدارة}

مقدمة

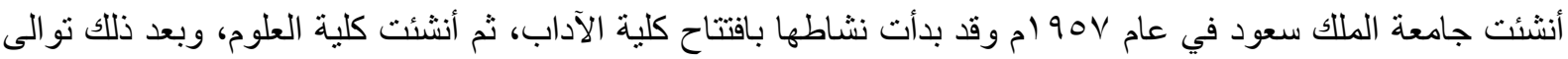

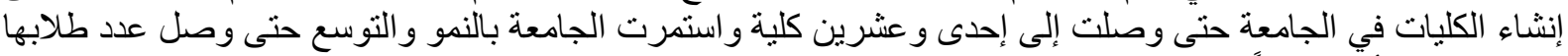

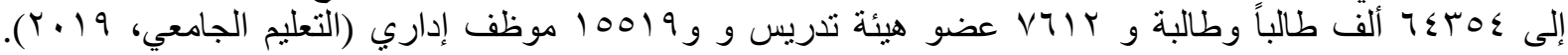

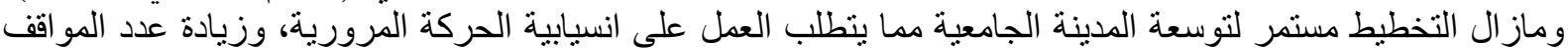

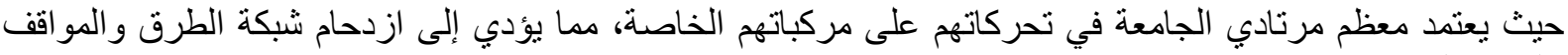

بالمدينة الجامعية. لقد بدأت مو اقف السيارات تجد اهتماماً متزايداً في ظل النمو الحضري الذي يشهده العالم منذ نهاية القرن التاسع عشر

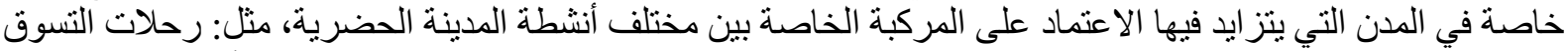

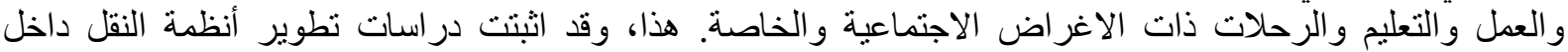

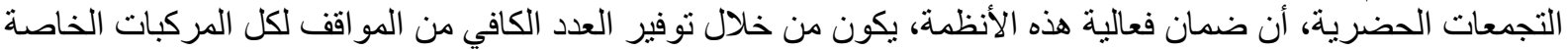

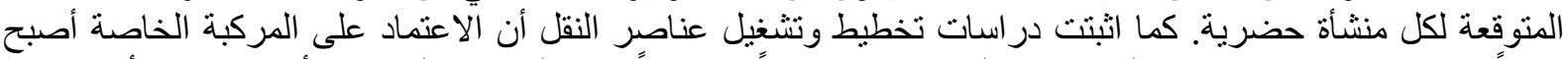

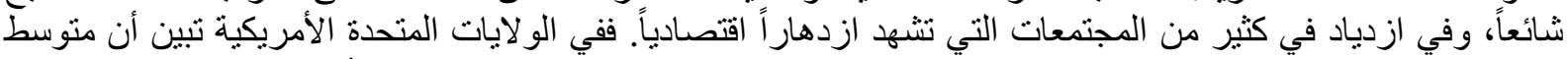

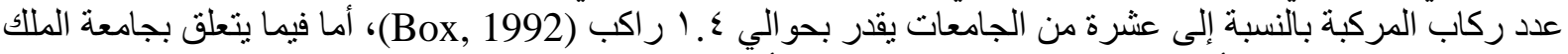

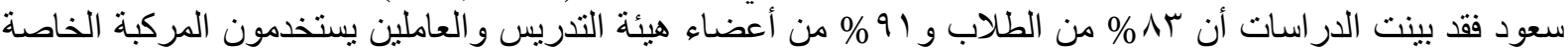

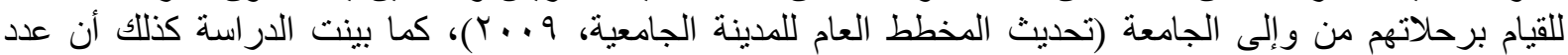

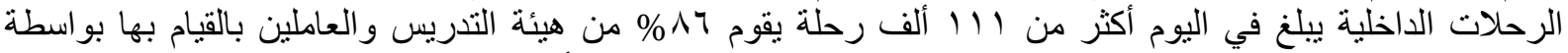

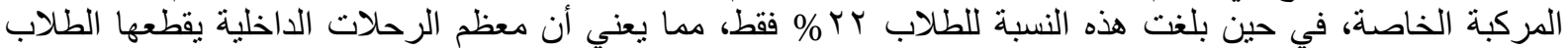

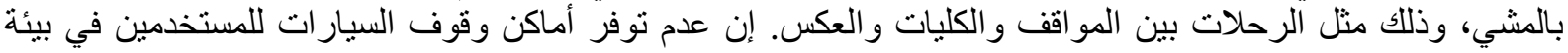

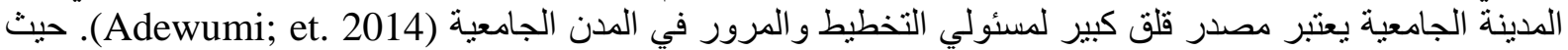

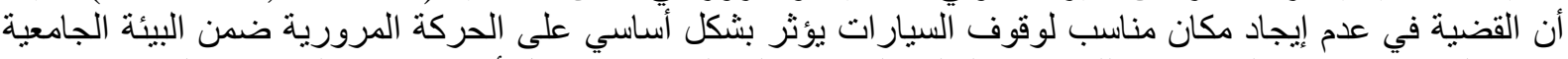

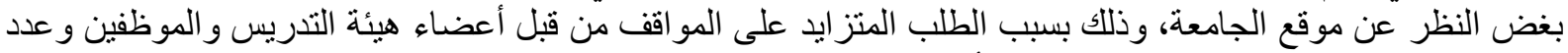
كبير من الطلاب، وبالتالي فإن النقص في أماكن وقوف السيارات يزيد من مشكلات الحركة والمراء المرور في الجامعات

.(Batabyal \& Nijkamp, 2010)

أهداف الاراسة

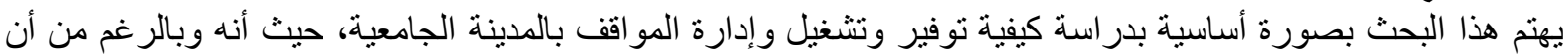

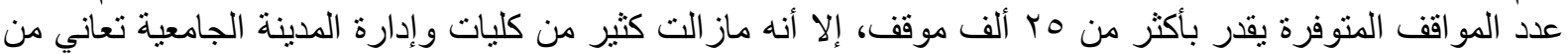

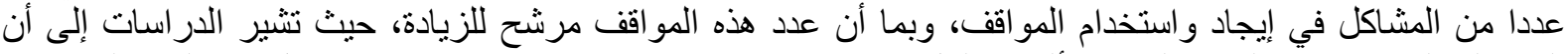

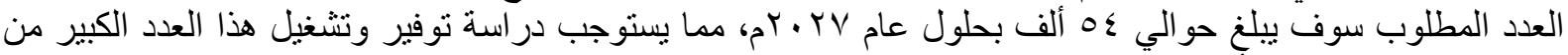

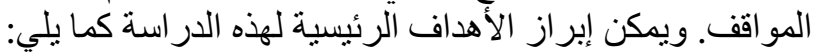

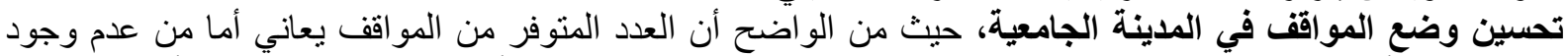

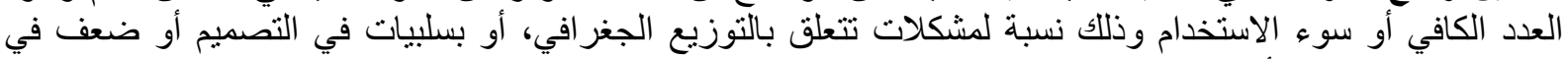

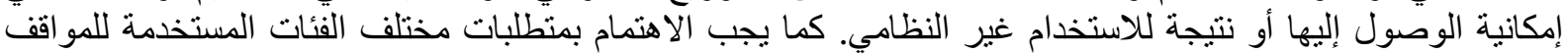

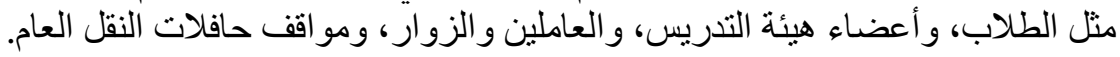




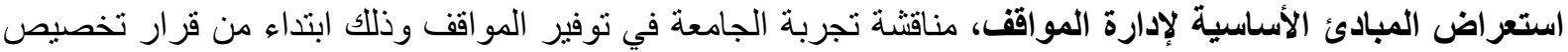

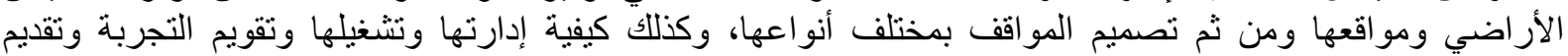

مقترحات لتحسينها.

استعراض مستجدات تقتية إدارة وتثفيل المواقف، من المهم أن تهتم الجامعة بتطبيق تقنيات متطورة لإدارة وتشغيل

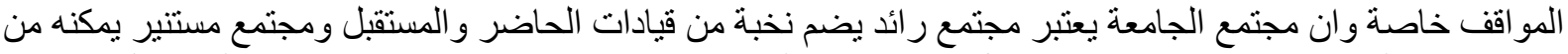

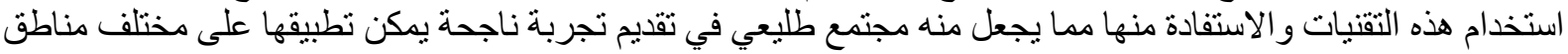

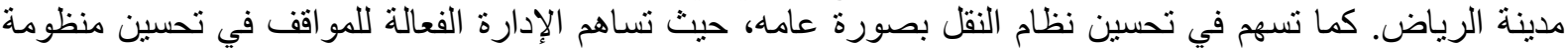

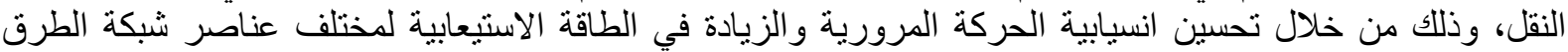

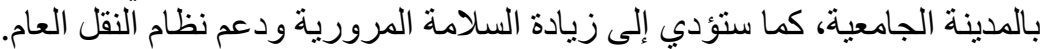

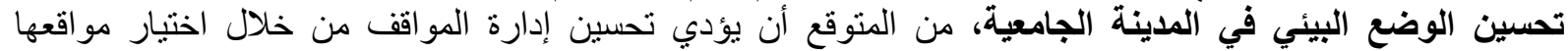

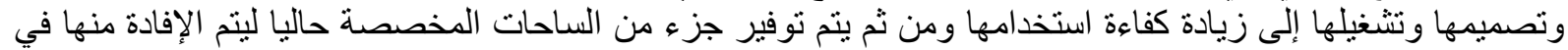

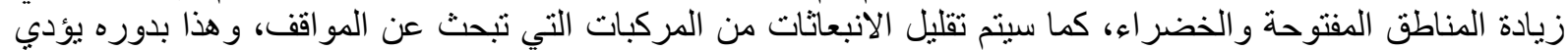
إلى تحسين البيئة في المدينة الجامعية.

أهمية مواقف السيارات وخصائص استخدامها

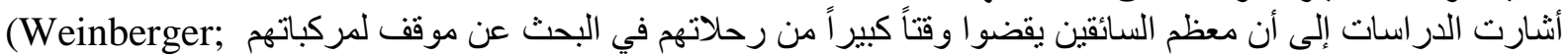

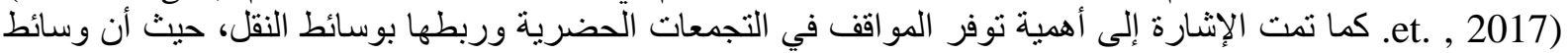

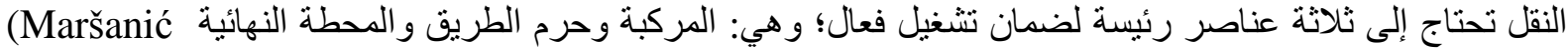

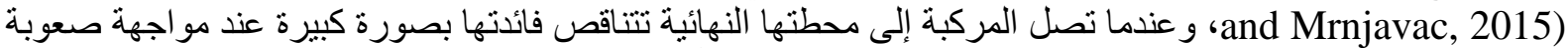

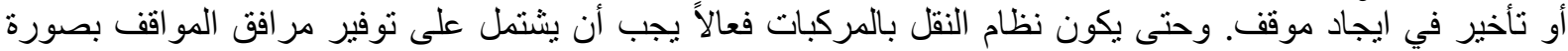

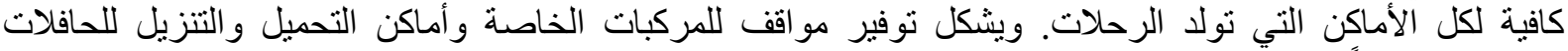

و الثاحنات تحدياً لمعظم التجمعات الحضرية (Shunk, 1990).

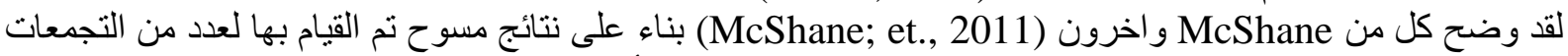

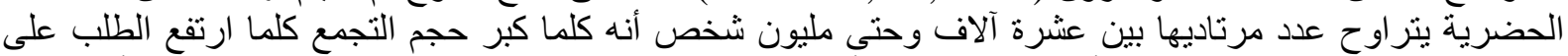

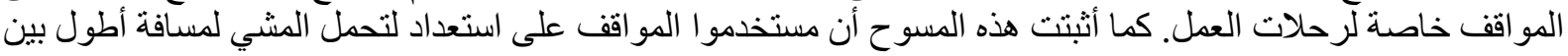
النوقف ومقصد الرحلة النهائي. أن خصائص المو اقف للجامعات و المدن الجامعية ترتبط بالكليات المختلفة والأنشطة الموجودة بهذه الجئه الجامعات. وتحتوي

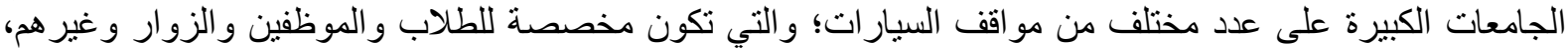

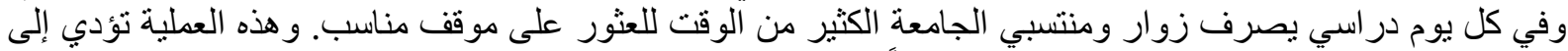

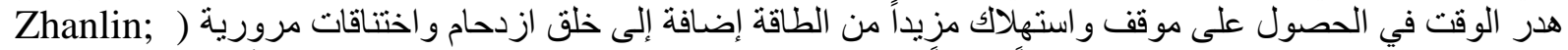

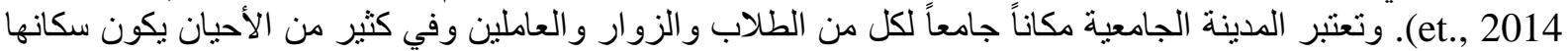

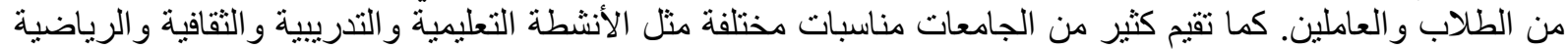

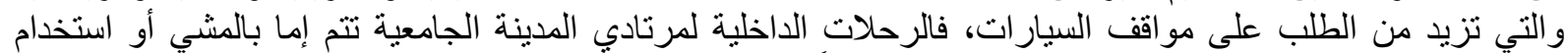

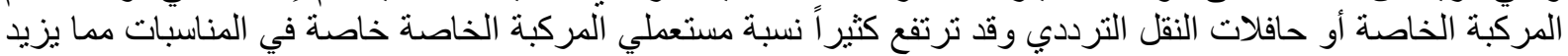
الضغط على الأماكن المخصصة لوقات النص التردي السيار ات ترع

الوضع الحالي لمنطقة الدراسة

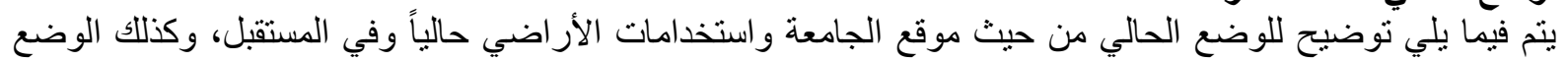
الحالي لثبكة الطرق بمختلف عناصر ها وحجم الحركة المرورية، وكذلك الإضافات و التحسينات المتوقع إدخالها على شبكة الطيا

موقع المدينة الجامعية

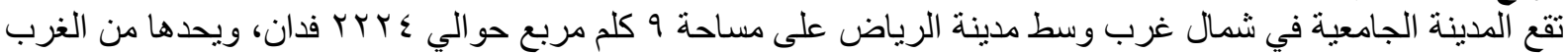

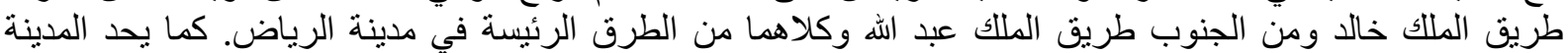

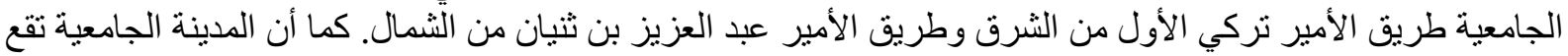

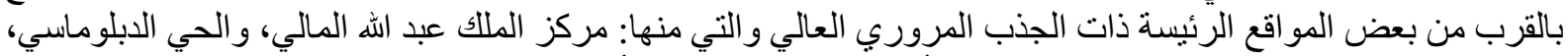
وشريط العصب التجاري و الذي تقع عليه معظم الأبر اج و البنايات عالية الأدوار ذات الاستخدامات التجارية والّكتيبية. 


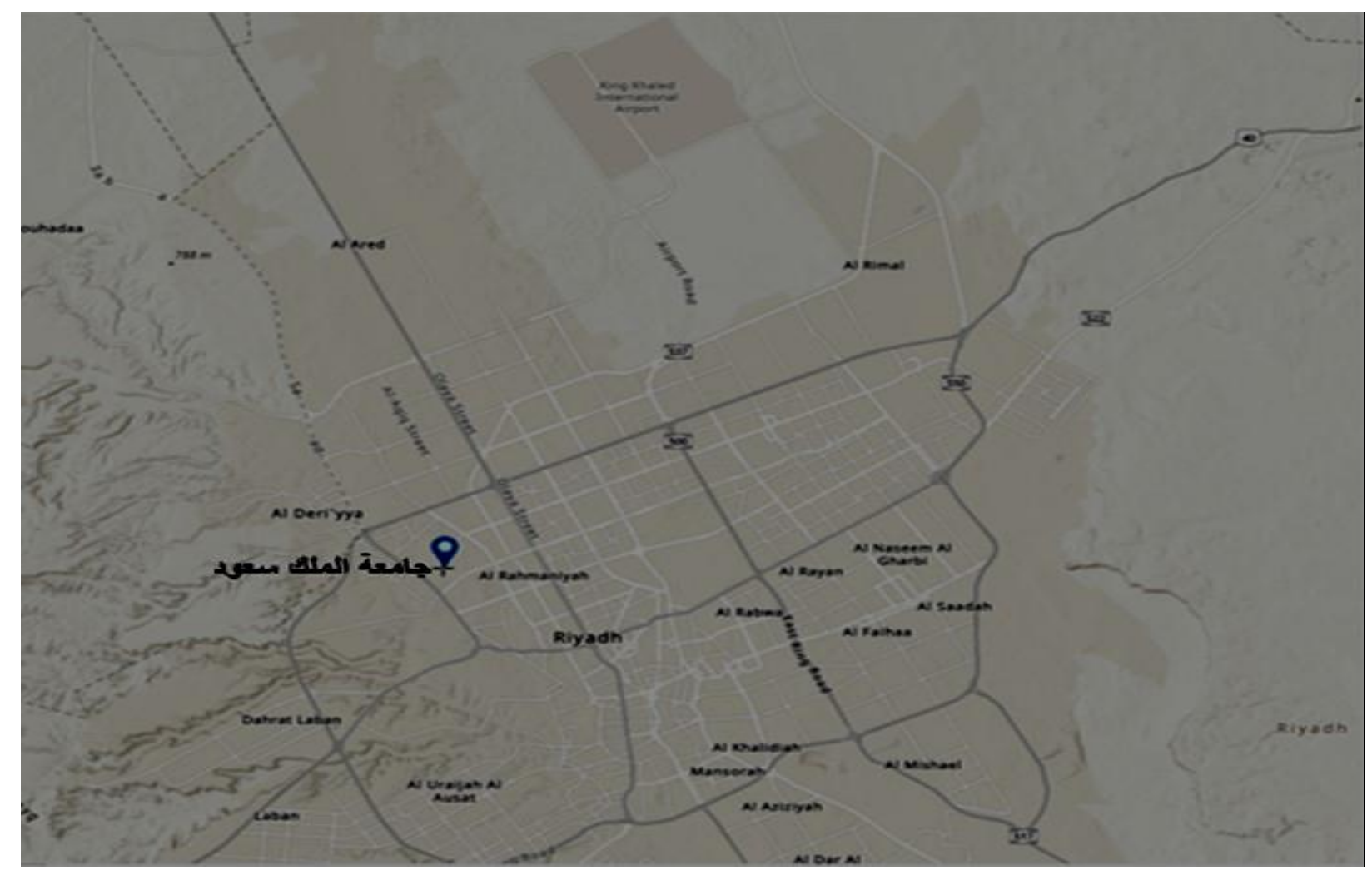

شكل ( ) موقع الجامعة في مدينة الرياض

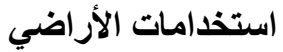

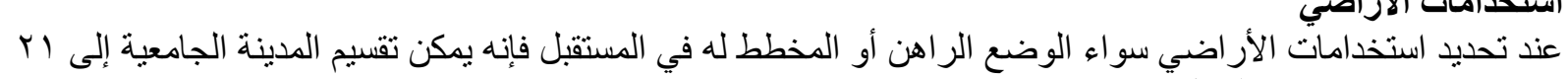

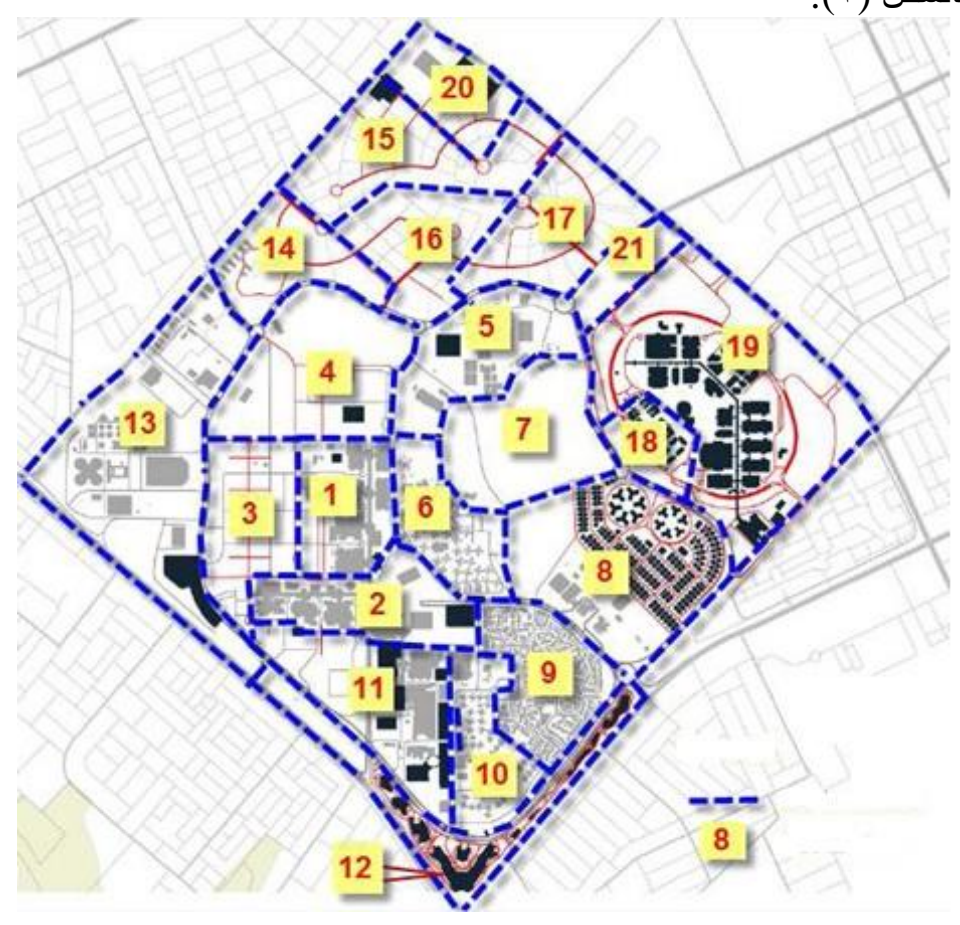

شكل (r) مناطق المدينة الجامعية

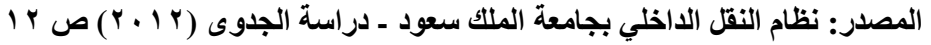

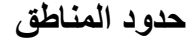

رقم المنطقة 
ويمكن توضيح الاستعمالات الرئيسية للأراضي سواء الحالية أو المستقبلية للمدينة الجامعية كما في الجدول (1) حيث يتضح وجود المو اقف كاستخدام ثابت في كثير من المناطق حالياو في المستقبل. جدول (1) استعمالات الأراضي في المدينة الجامعية

\begin{tabular}{|c|c|c|}
\hline الاستعمال المستقبلي للاراضي & الاستعمال الحالي للأراضي & المنطقة \\
\hline - مبنى لاتحاد الطلاب اض للعمادات المساندة & 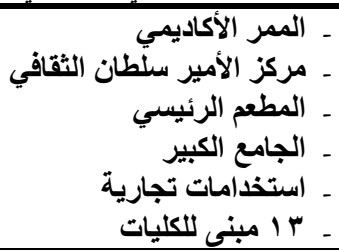 & منطقة الممر الأكاديمي وتثثمل المناطق \\
\hline & ـ ساحة مسطحة للمو اقف & 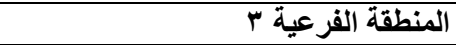 \\
\hline - ـ ألامتدادة الشمالي اللمدينةة الطبية (مرافق طبية ومراكز & ـ ـ ـ ـ العصاتب المركزي & المنطقة الفرعية ؛ \\
\hline - مبنى لمواقف سيارات متعدد الأدوار & ـ ـ م مرافقي كلية المدينة الرياضية البيةنة & المدينة الرياضية الفرية ه \\
\hline ـ ـ السكن الجدلاب الجدضيد & ـ ـ ـ السكن الحالي للطلاب مداب & المنطقة الفرعية 7 الطلاب \\
\hline & ـ ـ منطقة خالية & 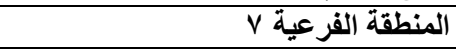 \\
\hline ـ ـ فنلادي وابرضاج لسكنة أعضاء هيئة التتريس & ـ مجمع مدارس & 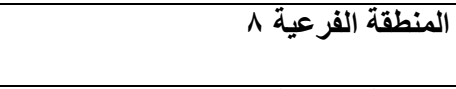 \\
\hline & 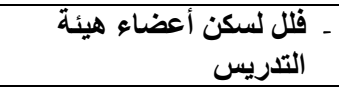 & المنطقة الفرعية 9 \\
\hline 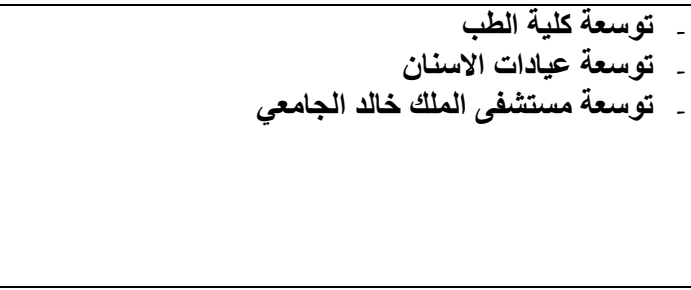 & 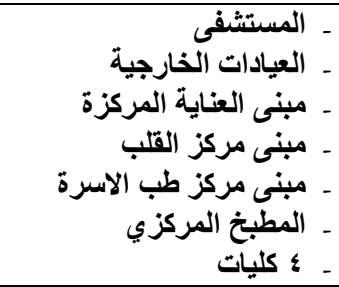 & 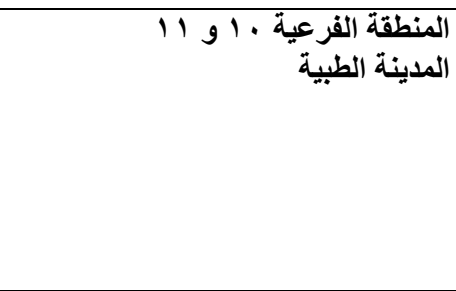 \\
\hline \multirow[t]{2}{*}{ 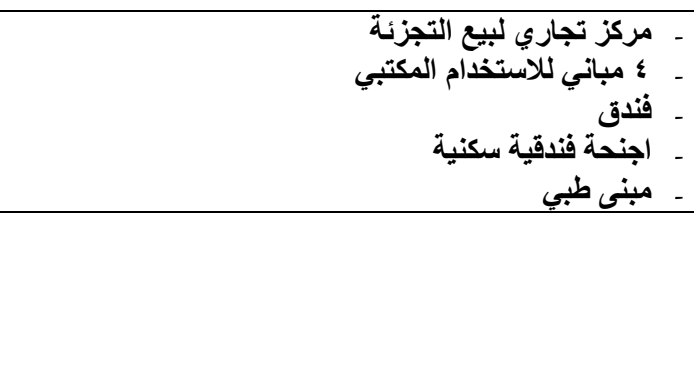 } & & 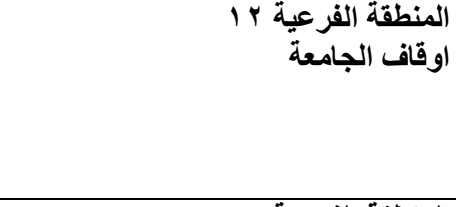 \\
\hline & ـ ـ ـ الخبنى الرئيسي لمركز & المنطقة الفرعية r II \\
\hline 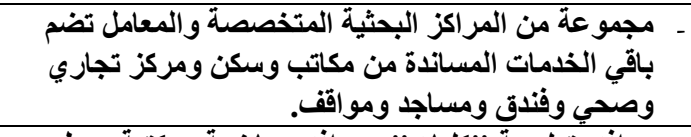 & & 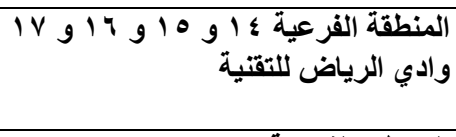 \\
\hline 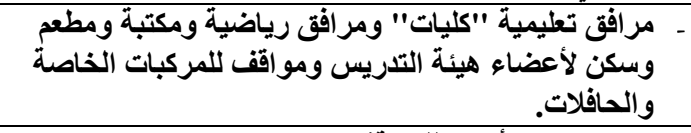 & & 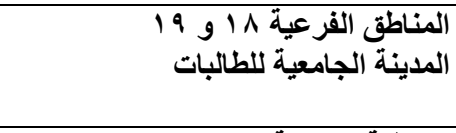 \\
\hline مبنى متعدد الأدوار للمواقف & ـ مو مباني السنة التحضيرية & كلية السنة التحضيرية المية \\
\hline ساحة مواقف لمستخذمي النقل العام داخل المدينة الجامعية & & المنطقة الفرعية ا Y \\
\hline
\end{tabular}

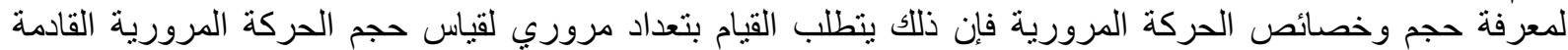

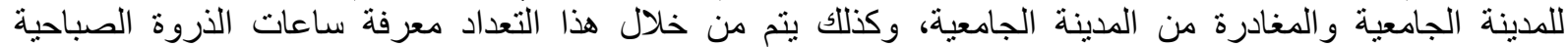

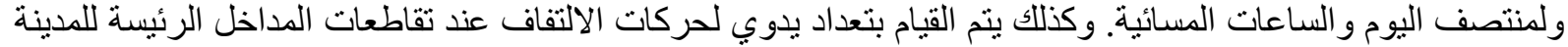

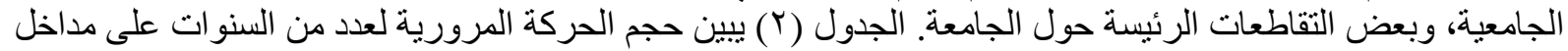




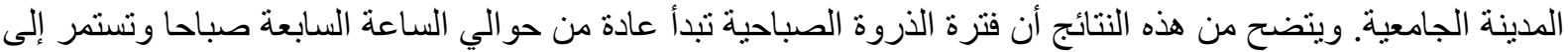

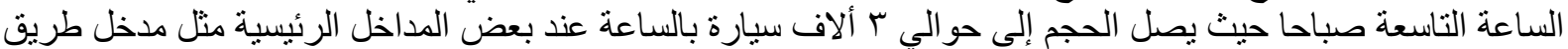

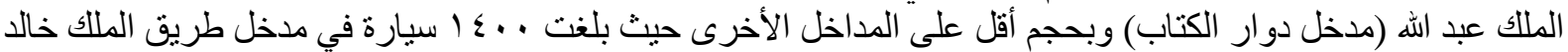

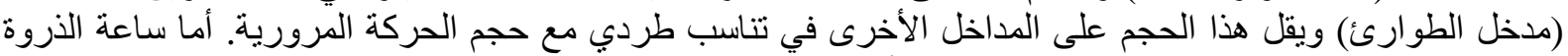

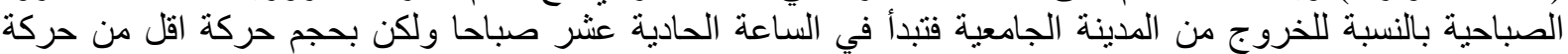

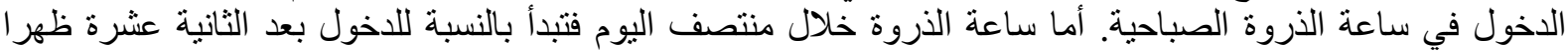

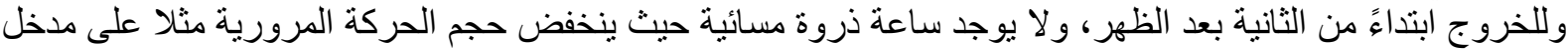

جدول (r) حجم الحركة المرورية على مداخل الجامعة (عدد السيارات)

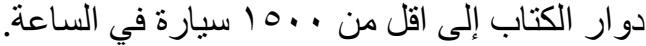

\begin{tabular}{|c|c|c|c|c|c|c|}
\hline \multicolumn{2}{|c|}{ مارس Y 1 +. } & \multicolumn{2}{|c|}{ 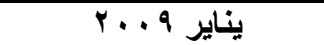 } & \multicolumn{2}{|c|}{ مارس V99 99} & \\
\hline خروج & لدخول & خروج & ل دخول & خروج & ل دخول & المدظل \\
\hline rorv. & rOYAO & rarro & Y $0 \leq \leqslant$. & YIVO. & $Y \cdot \Lambda \leq 0$ & دوار الكتاب \\
\hline $191 \ldots$ & IYAAD & $1 \leqslant Y T_{0}$ & IVVV. & rr^o & QYY. & الطوارئ \\
\hline $1 . \leqslant 0$. & $\$ 190$ & qAV० & $r v \ldots$ & 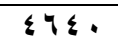 & TYY. & الخذمات \\
\hline $0 \leqslant$. & $1 \wedge \Lambda$. & $1 \leqslant 0$ & OYO & - & - & المستودعات \\
\hline r990 & rVr. & 17.10 & $1 \wedge \cdot 1$. & $1 \leqslant 0 \wedge 0$ & IYYAO & طريق الامام سعود \\
\hline IIVr. & ITYY. & $v \ldots$ & $\Lambda \leq 10$ & - & - & طريق الأمير عبدالعزيز بن \\
\hline 11100 & 71110 & 87990 & VYqr. & ะะห४. & $\varepsilon \leqslant \Delta V$. & المجموع الفرعي \\
\hline
\end{tabular}

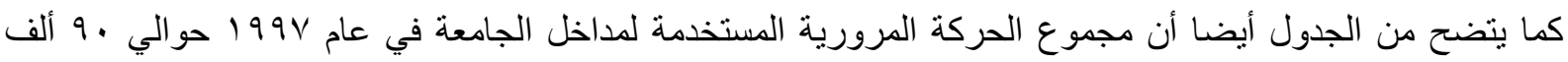

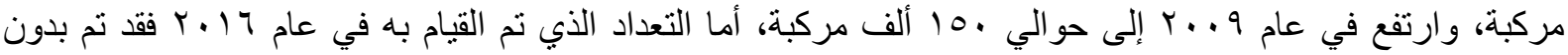

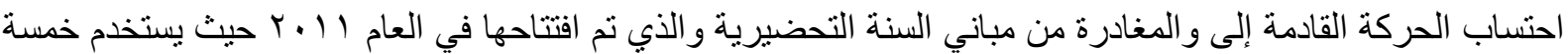

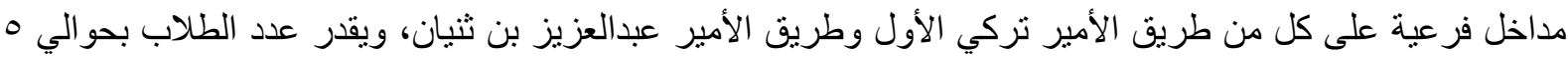

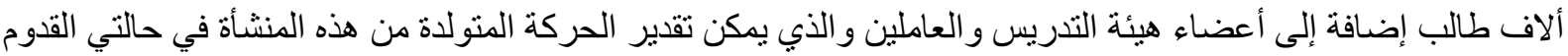

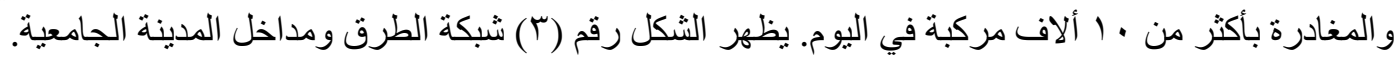

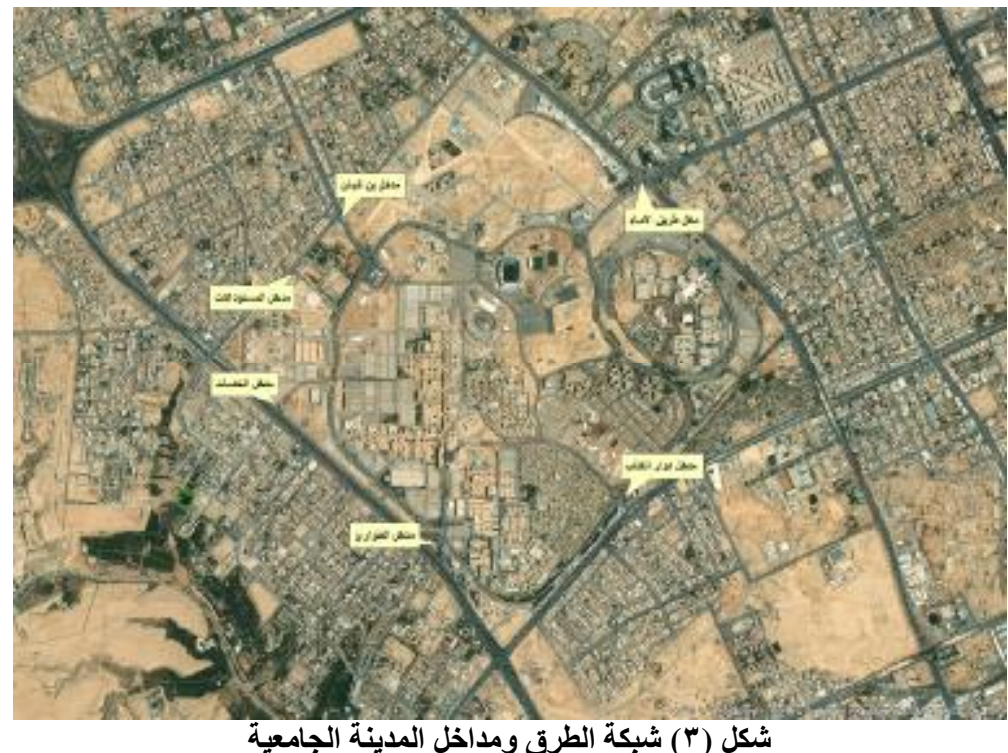

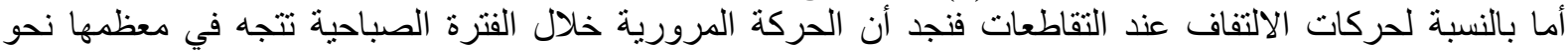

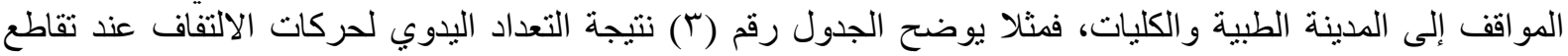

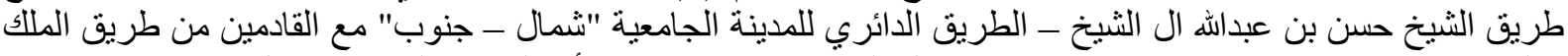
خالد "شرق - غرب" و هو ما يعرف بتقاطع مدخل الطوارئ، حيث يتضح أن الحركة القادمة من كل الاتجاهات متقاربة الفئ 
وذللك خلال فترة التعداد الممتدة من الساعة السادسة و النصف وحتى الساعة الثامنة و النصف صباحا. كما يتضح أن الحركة المتجهة إلى الجنوب باتجاه المدينة الطبية حيث المواعة القف هي الأكبر حجما.

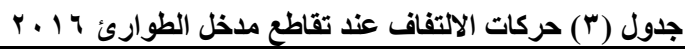

\begin{tabular}{|c|c|c|c|c|c|}
\hline المجموع & الغرب & الجنوب & الشرق & الشمال & من / إلى \\
\hline ITH & $1 \%$ & 070 & PVY & $\mu \wedge \mu$ & الشمال \\
\hline $1 V .0$ & P q & 11 & V & $\mu \varepsilon \wedge$ & الشرق \\
\hline $17 \leq 1$ & $r \leq 1$ & rVY & $V \vee \varepsilon$ & $10 \varepsilon$ & الجنوب \\
\hline 1 109 & - & 1. & 949 & YYY & الغزب \\
\hline$\triangle \wedge M \wedge$ & $\Delta V Y$ & 1179 & 1919 & 11.8 & المجموع \\
\hline
\end{tabular}

أهمية توفير مواقف السيارات للمدينة الجامعية

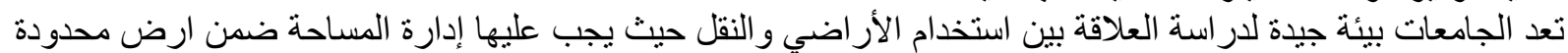

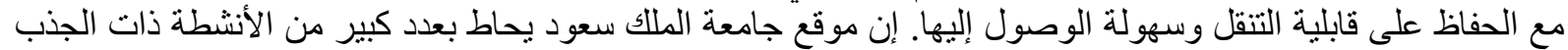

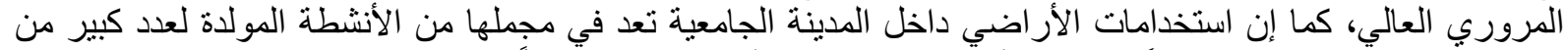

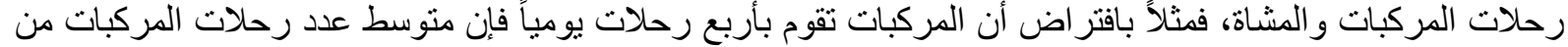

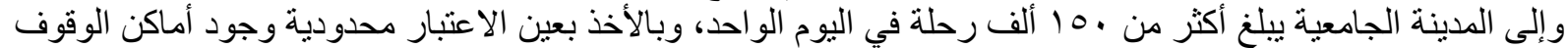

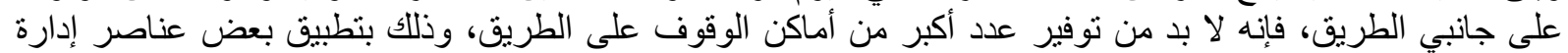

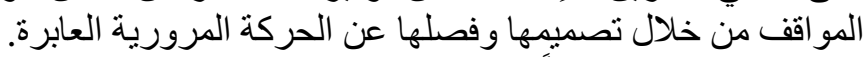

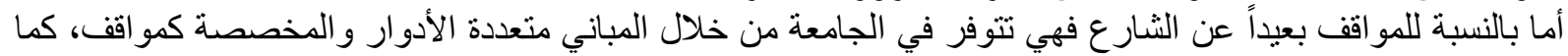

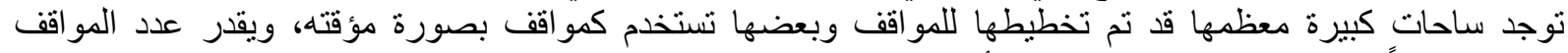

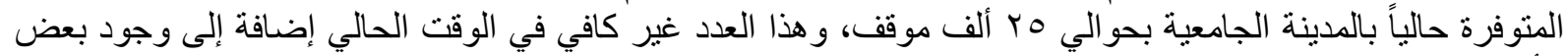

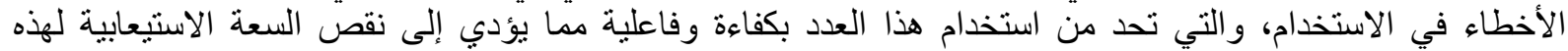

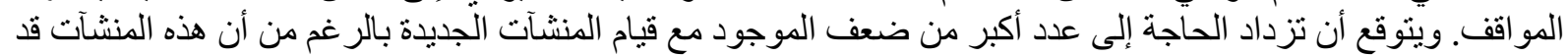

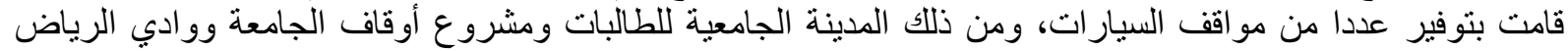

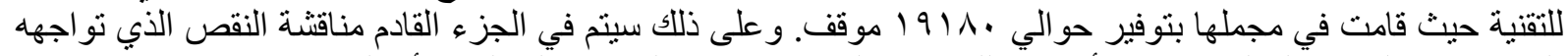
المو اقف في الوضع الحالي ودراسة أسباب ذللك سواءً النقص في عدد المو اقف الكطلوبة، أو النقص في طاقتها الاستيعابية

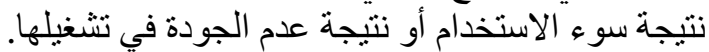

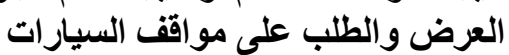

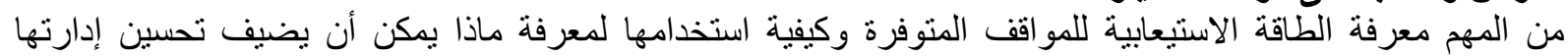

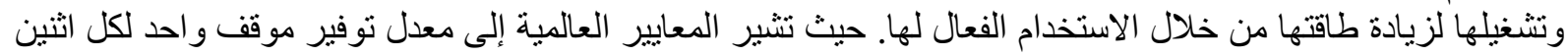

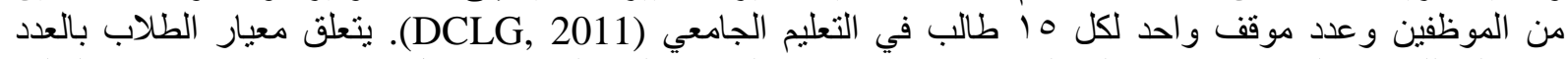

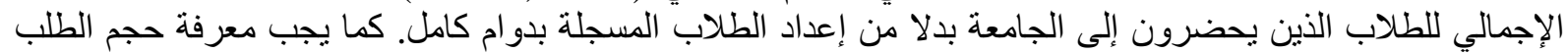

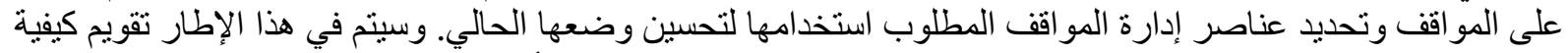

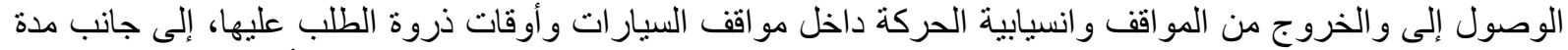

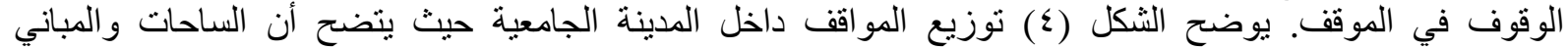
المخصصة كمو اقف تتركز بصورة رئيسة داخل المنطقة التي يحيط بها طريق الثيخ حسن إل الثنيخ (الطريق الدائري)

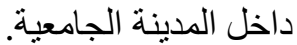




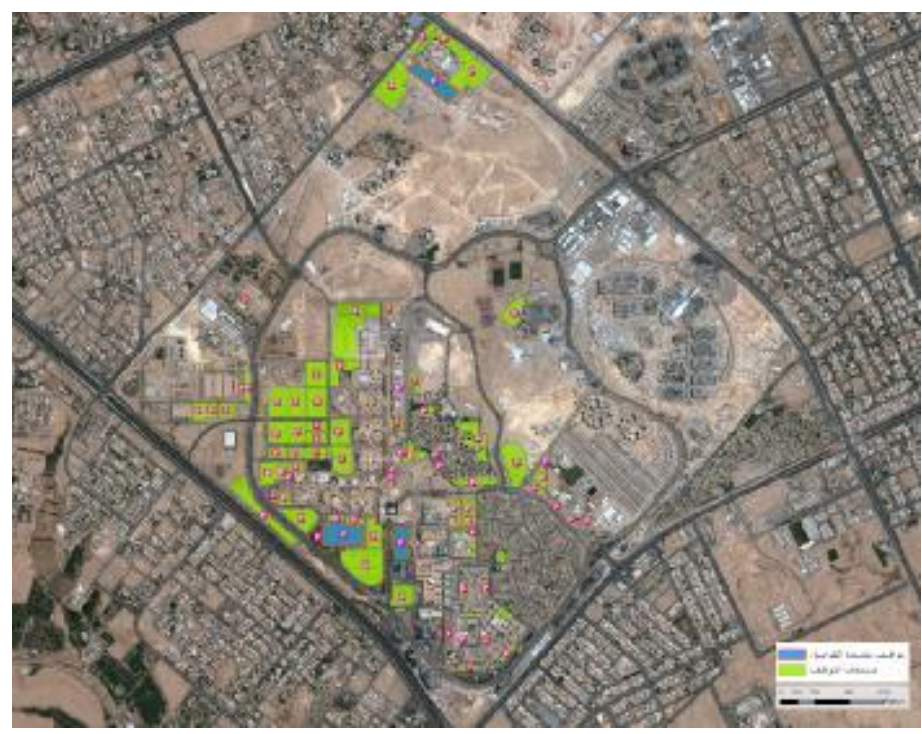

شكل (؛ ) المواقف داخل المدينة الجامعية

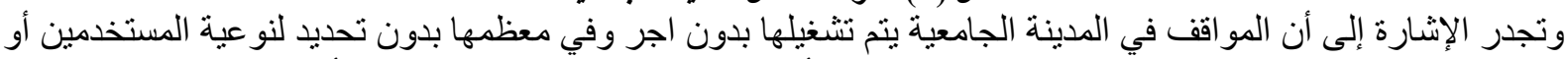
تحديد لوقت الوقوف المسموح به. كما يتضح محدودية أماكن الوقوف على جانبي الطرق أو الثوارع داخلية داخل المدينة

مواقف السيارات المتوفرة

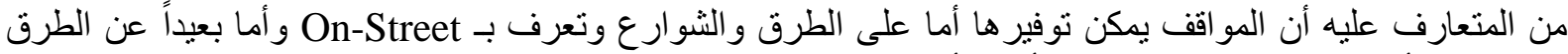

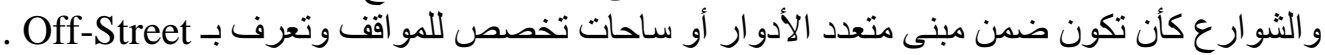

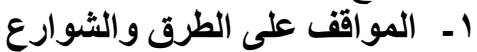

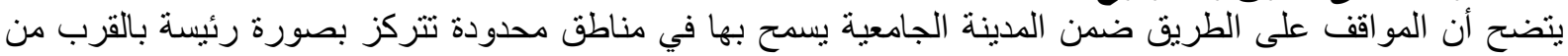

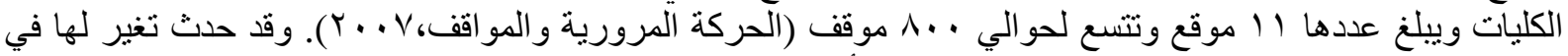

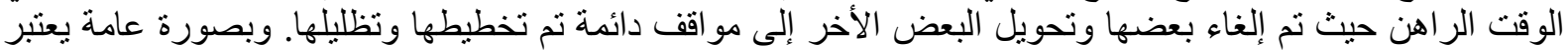

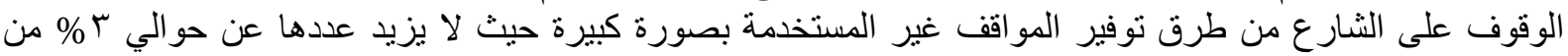

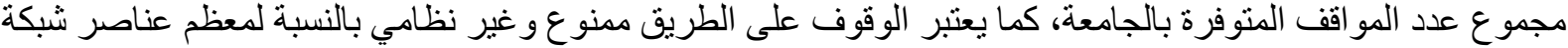

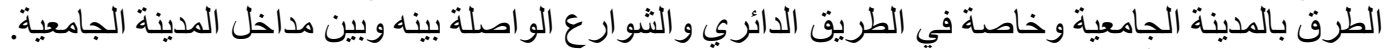

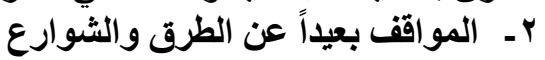

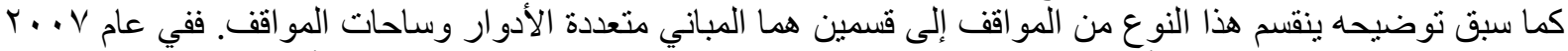

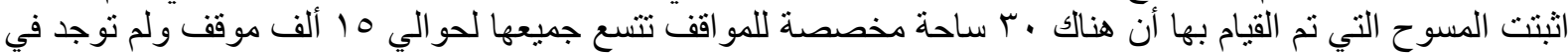

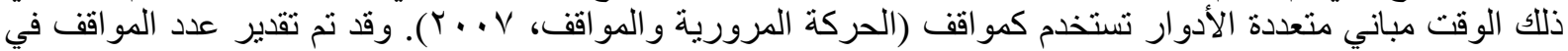

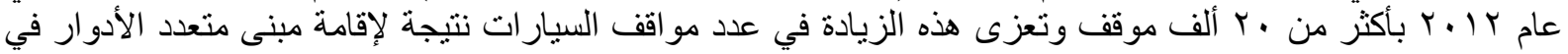

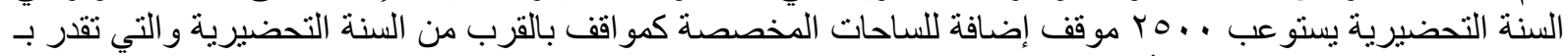

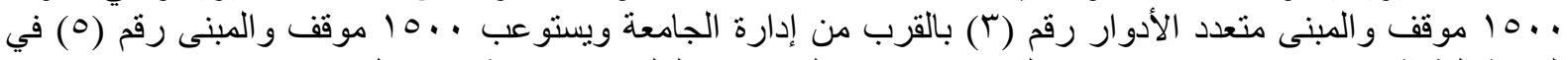

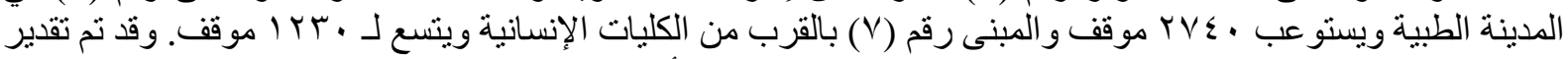

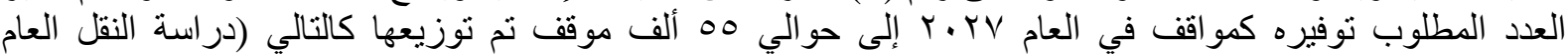

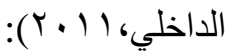

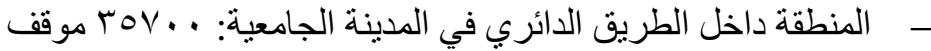

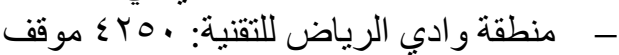

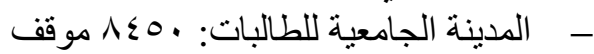

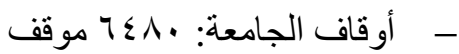

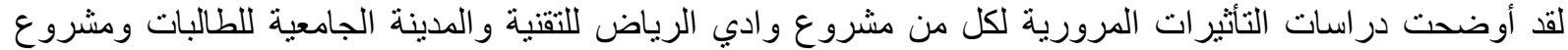

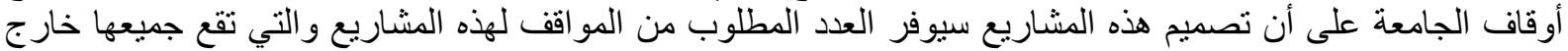
محيط الطريق الدائري. ويمكن تقدير النمو في وضع مواقف القان السيارات داخل محيط الطريق الدائري كما هو موضح 


\begin{tabular}{|c|c|c|}
\hline المرجع & عدد المواقف & 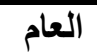 \\
\hline الحركة المرورية والمواقف & $10 \ldots$ & $r \cdots v$ \\
\hline دراسة النقل العام الداخلي & $r 1 \ldots$ & $r+11$ \\
\hline تقديري ومسوحات لهذه الدراسة & $r V \ldots$ & $r .17$ \\
\hline دراسة النقل العام الداخلي & $00 \ldots$ & $r \cdot r V$ \\
\hline
\end{tabular}

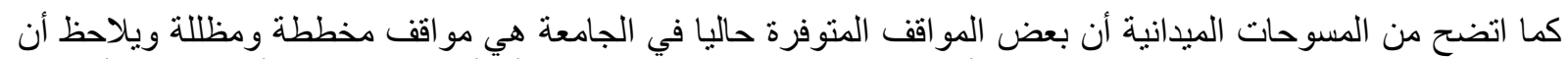

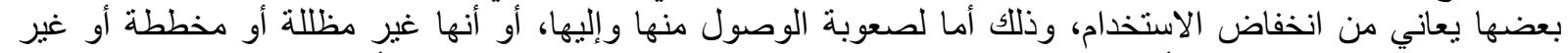

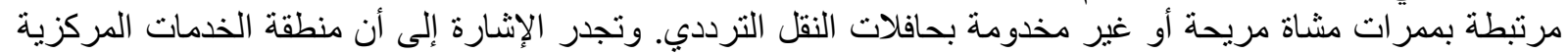

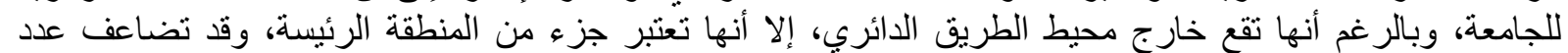

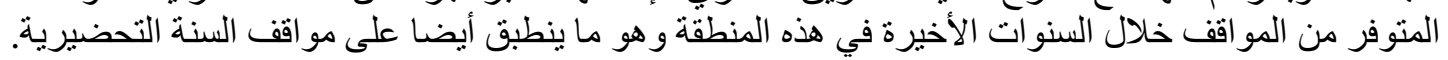

$$
\text { الطلب على مواقف السيارات }
$$

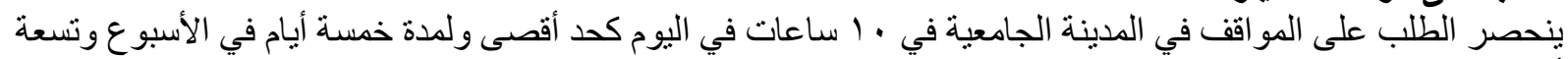

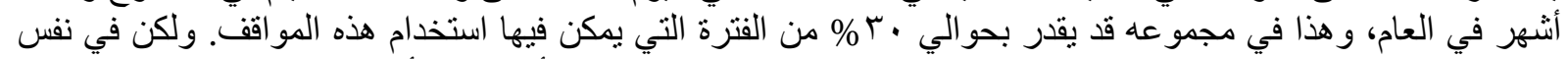

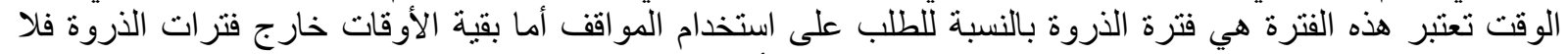

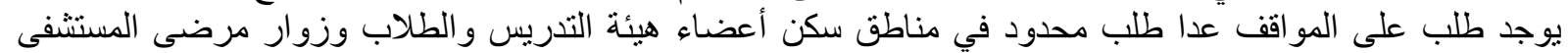
وبعض العاملين.

وفي المعتاد يتم تقدير الطلب على المو اقف بناء على عدة عو امل منها:

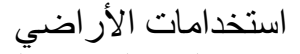
نسبة ملكية المركبة الخاصة الخماصة استخدام النقل العام داخل أو خارج التجمع الحضري

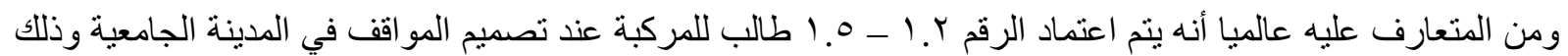

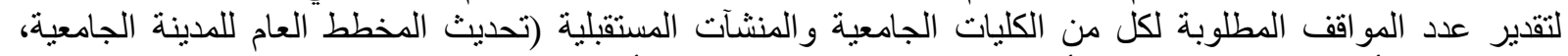

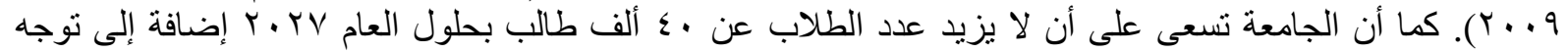

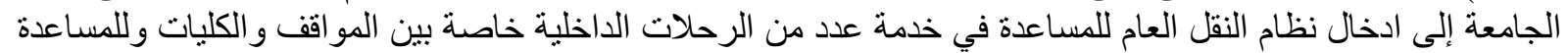
في اختيار مو اقع ساحات المواقف بعيدا عن مركز المدينة الجامعية.

\section{توافق العرض و الطلب على مواقف السيارات}

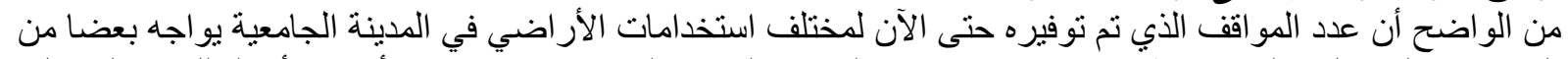

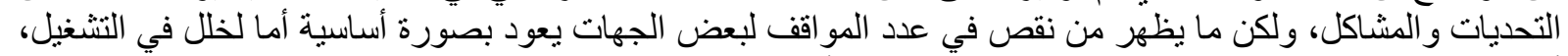

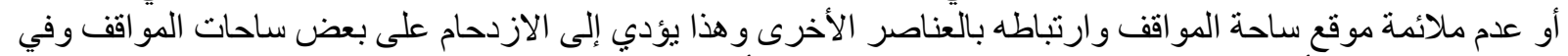

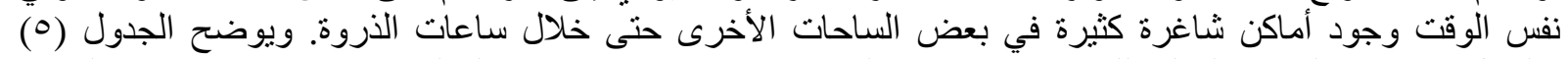

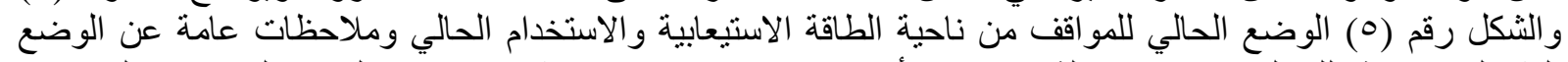

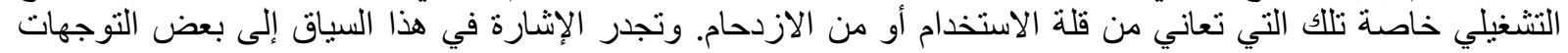

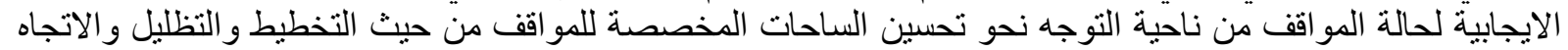

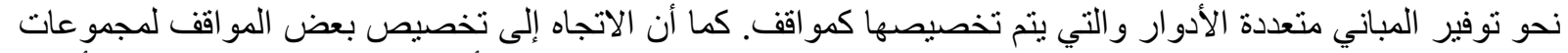

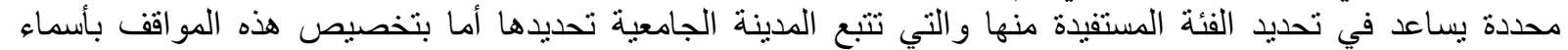

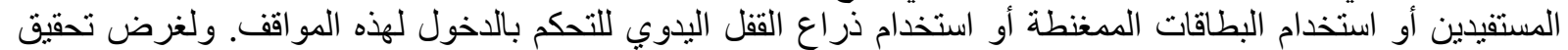

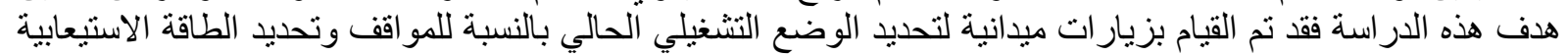

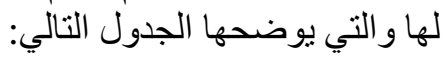


جدول (•) الوضع الحالي للمواقف بالمدينة الجامعية من حيث الطاقة الاستيعابية والتشغيل

\begin{tabular}{|c|c|c|}
\hline ملاحظات عن التشغيل & تقدير عدد المواقف & الرقم \\
\hline مكتبة الملك سلمان & ro & $\varepsilon r$ \\
\hline \multirow{2}{*}{ مخصصة لعمادة القبول والتسجيل } & $r \cdot$ & $\varepsilon r$ \\
\hline & Vq & $\varepsilon \leqslant$ \\
\hline مخصصة للجامع الكبيز & YIs & $\leqslant 0$ \\
\hline مواقف كلية علوم الحاسب & 119 & $\varepsilon 7$ \\
\hline مواقف لموظفي كلية علوم الحاسب & ro & $\leqslant V$ \\
\hline كلية العمارة والتخطيط & IV. & $\varepsilon \wedge$ \\
\hline \multirow{5}{*}{ التدريس والموظفينة بكن اعضاء هيئة } & 149 & $\{9$ \\
\hline & \&1 & 0. \\
\hline & rq1 & 01 \\
\hline & Yr & Or \\
\hline & 11 & Or \\
\hline السوق التجاري & 90 & $0 \leqslant$ \\
\hline كلية العلوم الطبية التطبيقية & 7. & 00 \\
\hline \multirow{7}{*}{ التدريس التكنية بسكن اعضاء هيئة } & $1 \ldots$ & 09 \\
\hline & $\Lambda$. & $\Delta V$ \\
\hline & $\Lambda$. & $\Delta \wedge$ \\
\hline & vo & 09 \\
\hline & 7. & 9. \\
\hline & $1 \ldots$ & 71 \\
\hline & $1 \ldots$ & Ir \\
\hline تابع لمبنى المواقف (•) & $r \leqslant$ & 74 \\
\hline \multirow{2}{*}{ مخصصة لموظفي الخدمات } & $\wedge 7$ & $7 \leq$ \\
\hline & 110 & 70 \\
\hline \multirow{6}{*}{ العولة موتف مفتوحة يستخدمها طلاب الكليات } & $\varepsilon \ldots$ & 79 \\
\hline & $\varepsilon \cdot q$ & $7 V$ \\
\hline & $7 \leq \leqslant$ & 71 \\
\hline & $0 \leqslant$. & 79 \\
\hline & $\varepsilon Y$ & $V \cdot$ \\
\hline & $1 \leq$ & VI \\
\hline مطابع الجامعة & $\wedge$. & VY \\
\hline مواقف مؤقته & 1.10 & Vr \\
\hline السنة التحضيرية & $r \ldots$ & $V \varepsilon$ \\
\hline \multirow{2}{*}{ التحضيرية لهيئة التتريس وموظفي السنة } & rir & Vo \\
\hline & $r \cdot \Lambda$ & 187 \\
\hline طلاب السنة التحضيرية & $9 \leq \Lambda$ & $V V$ \\
\hline \multirow{2}{*}{ مستثفى الملك خالد الجامعي } & $r \varepsilon$ & $\vee \wedge$ \\
\hline & $\sqrt{17}$ & 199 \\
\hline مخصصة للعاملين في صيانة السكن & $r \cdot$ & $\wedge$. \\
\hline \multirow{2}{*}{ كليتي التربية والآداب } & 0. & $\wedge 1$ \\
\hline & $1 \cdot r$ & $\Lambda Y$ \\
\hline المجموع الكلي & $r 0 \leq 71$ & - \\
\hline
\end{tabular}

\begin{tabular}{|c|c|c|}
\hline ملاحظات عن التشغيل & تقدير عدد المواقف & 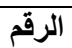 \\
\hline مواقف مفتوحة & $10 \ldots$ & 1 \\
\hline مخصص لطلاب كلية الطب & $99 \varepsilon$ & $r$ \\
\hline مخصص لموظفي مبنى IV & rra & $r$ \\
\hline مواقف مفتوحة & $1 \leqslant$. & $\varepsilon$ \\
\hline مواقف مفتوحة & $r \ldots$ & 0 \\
\hline مخصص لموظفي كلية الحقوق & $10 \leqslant$ & 7 \\
\hline مواقف مفتوحة م & $1 \% \ldots$ & $\mathrm{V}$ \\
\hline \multirow{2}{*}{ مخصص لطلاب كلية العلوم } & $\leqslant 00$ & $\Lambda$ \\
\hline & $\varepsilon \cdot \varepsilon$ & 9 \\
\hline \multirow{2}{*}{ مخصص لمركز الامير سلطان الثقافي } & VV & 1. \\
\hline & $\Lambda$. & 11 \\
\hline \multirow{3}{*}{ مخصص لكلية إدارة الاعمال } & $9 \ldots$ & ir \\
\hline & ro. & ir \\
\hline & IY. & $1 \varepsilon$ \\
\hline مواقف تخذمها حافلات النقل الترددي & $9 \mathrm{rA}$ & 10 \\
\hline \multirow{7}{*}{ 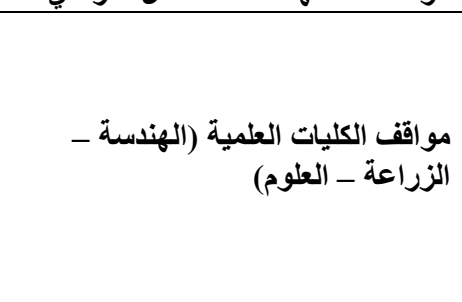 } & $r \leqslant Y$ & 17 \\
\hline & $r \leqslant r$ & IV \\
\hline & 11. & 11 \\
\hline & 11. & 19 \\
\hline & $1 \leqslant$ & $r \cdot$ \\
\hline & $1 \leq 7$ & Y \\
\hline & rOY & rY \\
\hline \multirow{2}{*}{ مواقف كلية اللغات والترجمه } & $r \cdot \Lambda$ & $r r$ \\
\hline & YIr & $r \varepsilon$ \\
\hline \multirow{2}{*}{ مواقف للموظفين لكلية اللغات والترجمة } & 179 & ro \\
\hline & \& & YY \\
\hline مخصصة لكليتي الحقوق والتربية & $\varepsilon r \wedge$ & $r V$ \\
\hline مخصصة لموظفي المستشفى & $\varepsilon \ldots$ & $r \wedge$ \\
\hline \multirow{2}{*}{ مخصص لمركز الاميز سلطان الثقافي } & $\Lambda$. & rq \\
\hline & $\Lambda$. & $r \cdot$ \\
\hline مواقف مفتوحة & $r \cdot \Lambda$ & 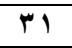 \\
\hline مخصص لسيارات النقل & $\Lambda V$ & rr \\
\hline مو اقف خاصة بالصيانة & $1 \cdots$ & $r r$ \\
\hline مو اقف خاصة بالملاعب & 97 & $r \varepsilon$ \\
\hline تمت ازالته لتوسعة السكن & $\Lambda \cdots$ & ro \\
\hline \multirow{6}{*}{ مواقف للمدراس - مجمع الملك سعود } & $r$ & ry \\
\hline & IVV & $r v$ \\
\hline & $1 \cdots$ & $r \Lambda$ \\
\hline & o. & rq \\
\hline & 7. & $\varepsilon$ \\
\hline & $r \varepsilon$ & $\leqslant 1$ \\
\hline
\end{tabular}




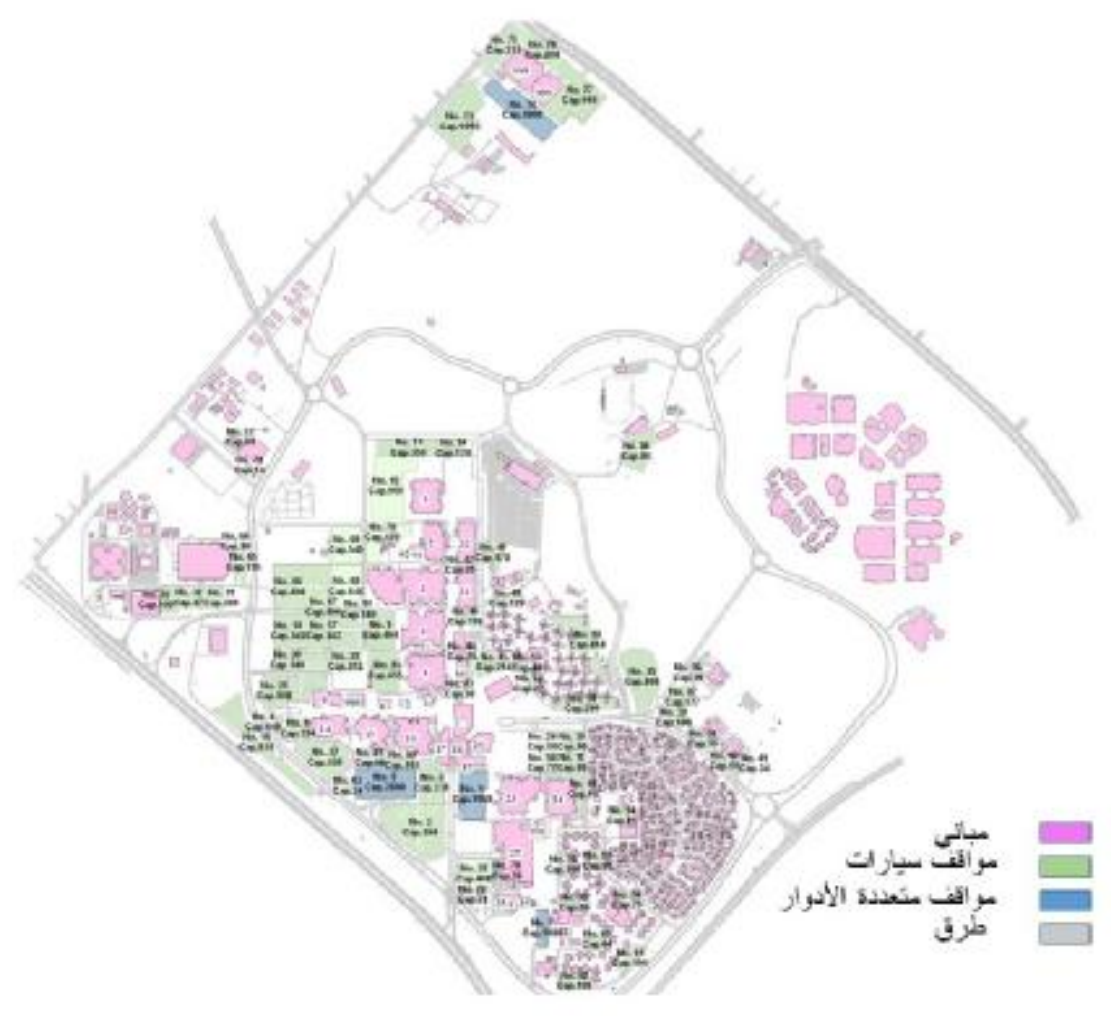

شكل (•) الطاقة الاستيعابية لمواقف السيارات

سياسات توفير وإدارة مواقف السيارات

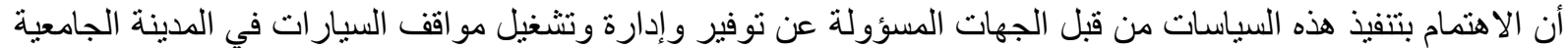

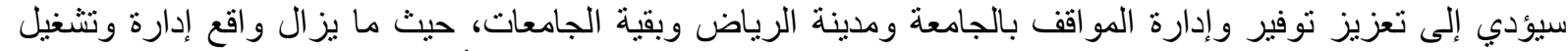

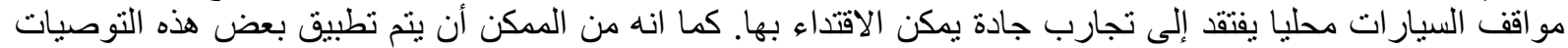

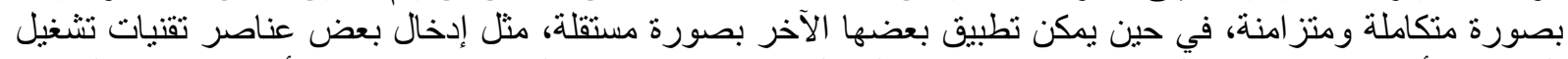

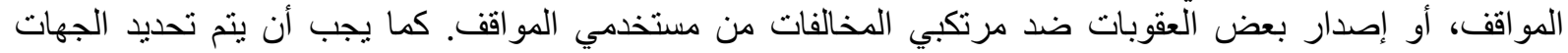

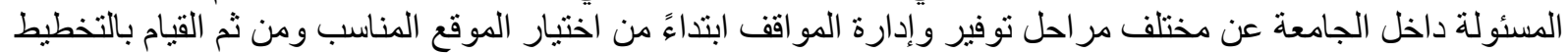

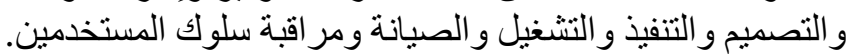
نظام أو قانون وقوف السيارات هو مجموعة من السياسات التي تستخدم لإدارة مو اقف السيار ات و والتي تدعم إستراتيجية تنظيم الفر اغات المخصصة لمو اقف السبارات في المناطق العمرانية (Milosavljević and Simićević, 2018).

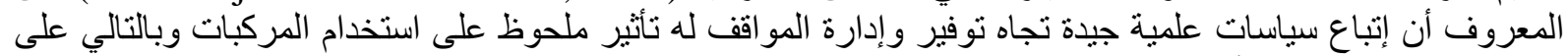

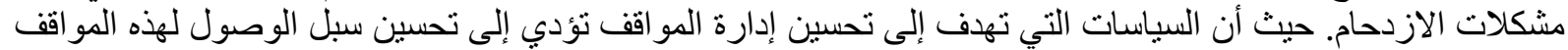

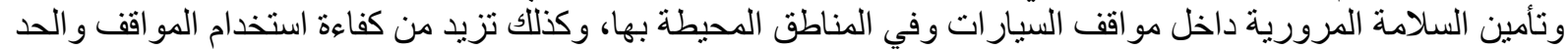

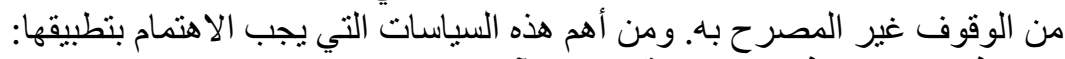

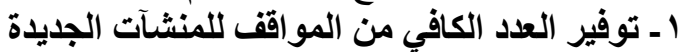
بما أن الجامعة تشهد حركة نمو مضطردة تلتطلب تشييد المزيد من المباني لمختلف استخدامات الأراضي، وهذا يتطلب توفير المزيد من المو اقف من نـاحيتي:

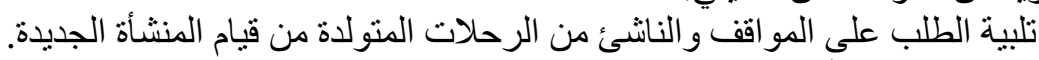

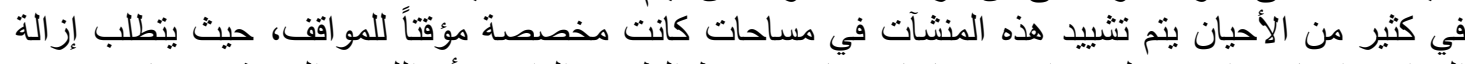

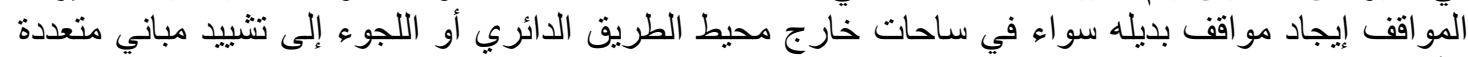

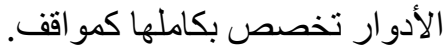
r ـ الحد من الطلب على المو اقف واختيار الموقع المناسب

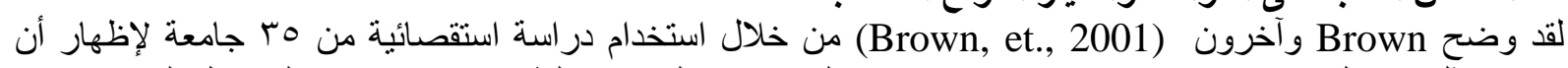

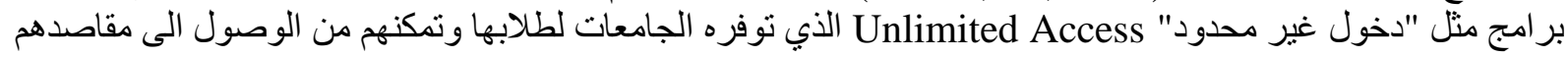




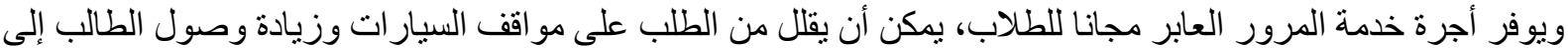

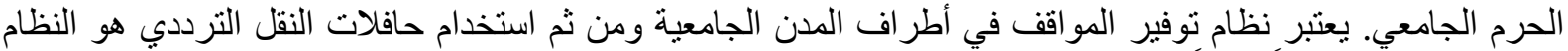

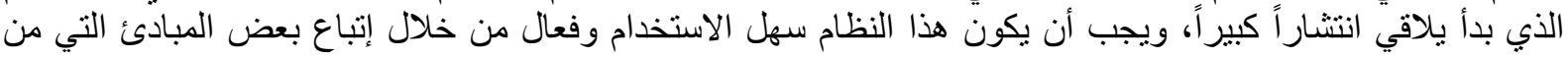

برمجه جيده و إتباع فترة بين الحافلتين لا تتعدى ه إلى • ل إدقائق اعتمادا على الطاقة الاستيعابية للحافلة. بينها:

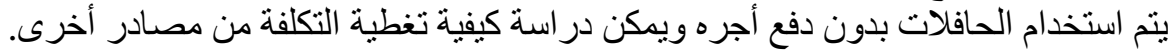
يتم استخدام الحافلات بدون إبراز الحئ لهوية محددة.

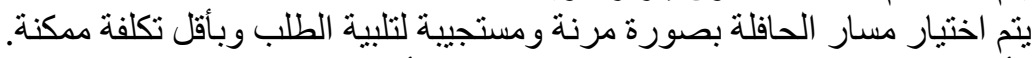
من المؤكد أن إتباع سياسة توفير المو اقف لا تمثل الحل الأمثل خاصة في حالة تخصيص ساحسات كمو اقف في وسط المدينة

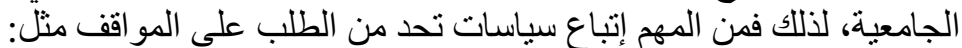

استخدام النقل العام سو اء للوصول للمدينة الجامعية، وذللك عند تطبيقه على مستوى مدينة الرياض، أو الو استخدام النقل العام في الرحلات داخل الجامعة وهذا سيتيح للجامعة تخصيص ساحات المواقف في أطر اف المدينة

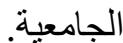
تشجيع الطلاب على استخدام المركبة الواحدة لأكثر من طالب وذللك بتوفير مواقف خاصة تكون قريبة من الكليات أو سهل الوصول إلئهاب.

توفير بيئة مشاه آمنه ومريحة الئها لتشجيع القيام بالرحلات القصيرة مشياً، وخاصة بالنسبة لسكان المدينة الجامعية.

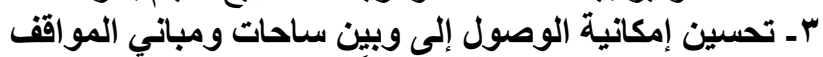

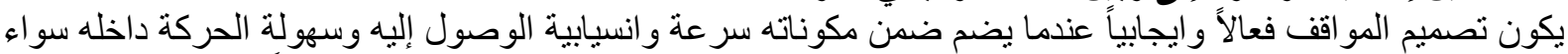

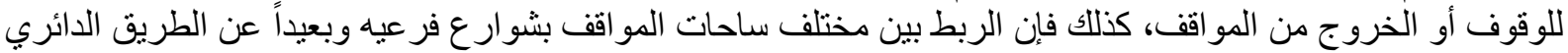

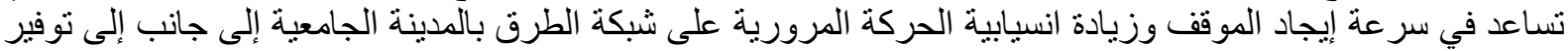

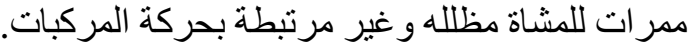

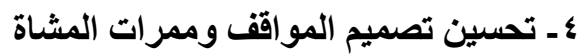

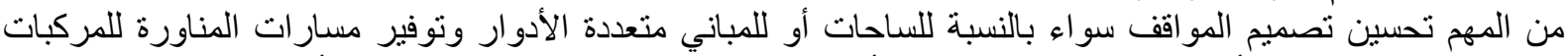

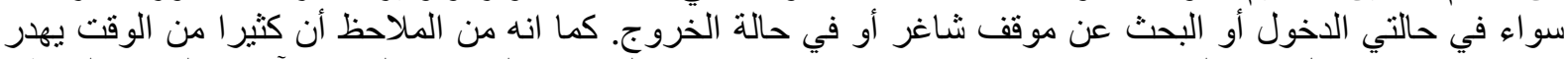

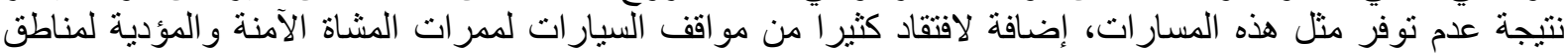

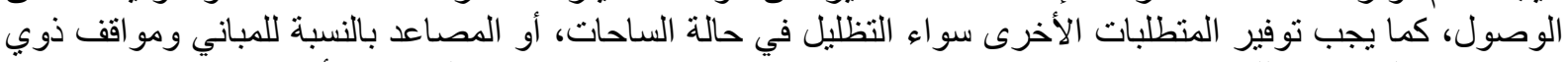

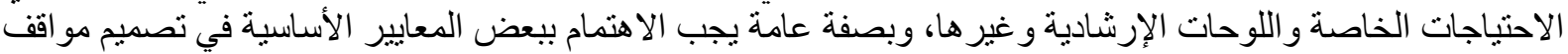

توفير مسار ات تؤمن انسيابية الحركة من و إلى وداخل ساحات المو اقف.

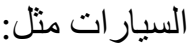

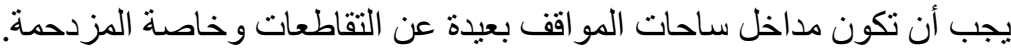

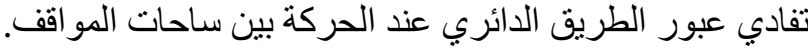

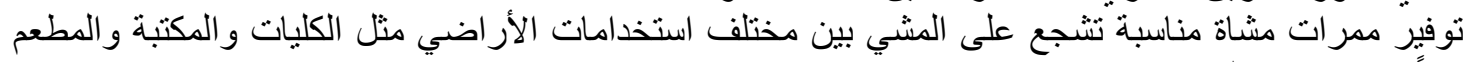
بدلاً من استخدام المركبة.

هـ استخدام اللوحات الإرشادية

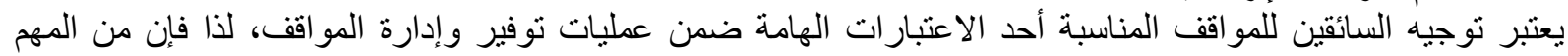

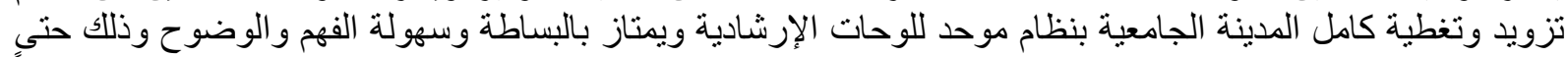

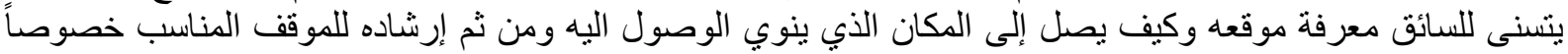

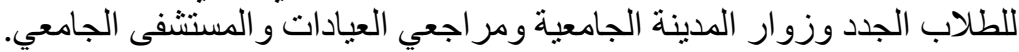

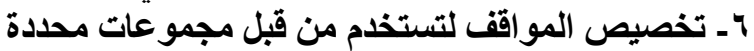

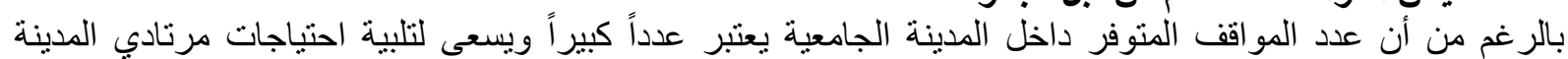

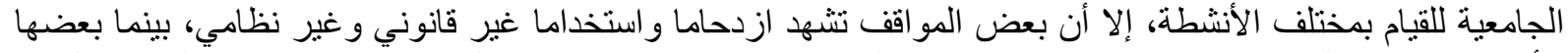

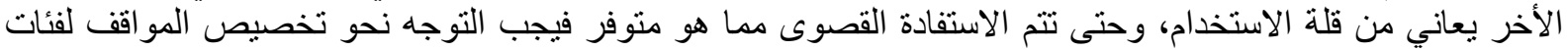

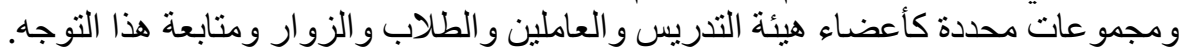

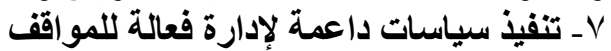

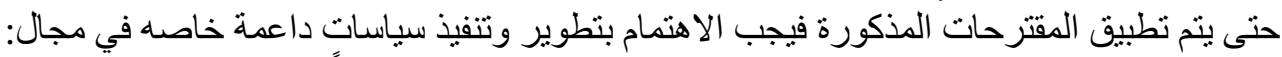

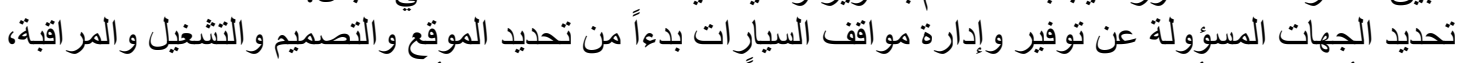

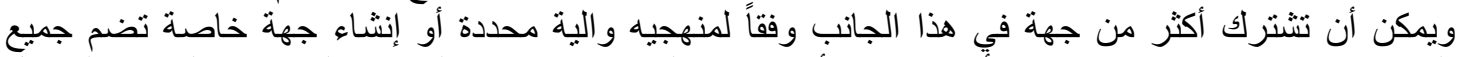

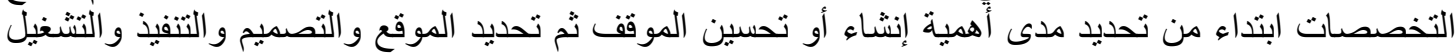

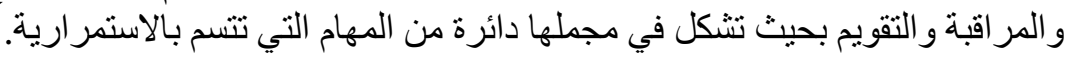


استخدام أنظمة النقل الذكي Intelligent Transport Systems و هذه الأنظمة تشهد تطوراً وتطبيقاً في كثير

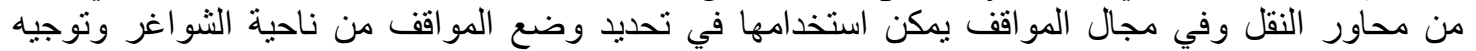
السائقين لأقرب موقف و المساعدة في التحكم في تشغيل المو اقف المخصصة سو اء من خلال البطاقات الممغنطة

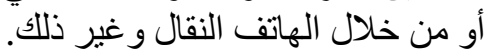
وضع وتطبيق عقوبات محددة للمخالفين و الذين يستخدمون المو اقف بصورة غير نظامية.

تحتاج المدن الجامعية إلى حلول فعالة لمشاكل الطلب المتز ايد على مو اقف السيارات وما يصاحبها من الازدحام و الاستخدام

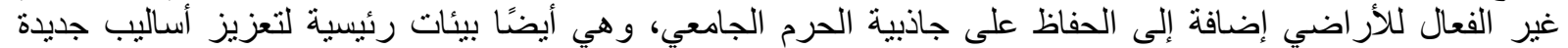

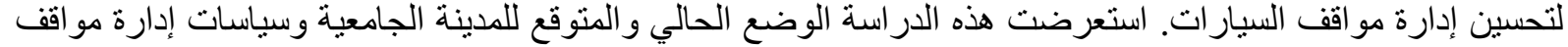

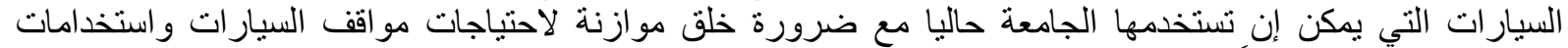

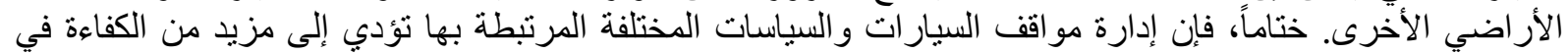

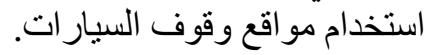

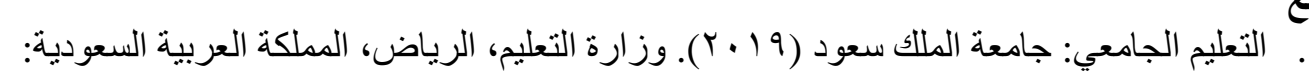

https://www.moe.gov.sa/ar/HighEducation/Government-Universities/Pages/KSU.aspx

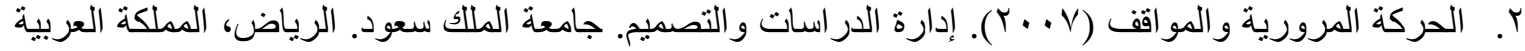

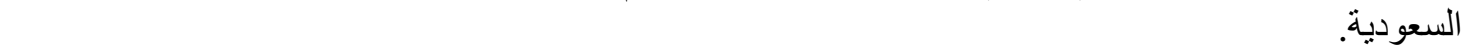
r. دراسة النقل العام الداخلي (11) (1). وكالة الجامعة للمشاريع. جامعة الملك سعود. الرياض، المملكة العربية

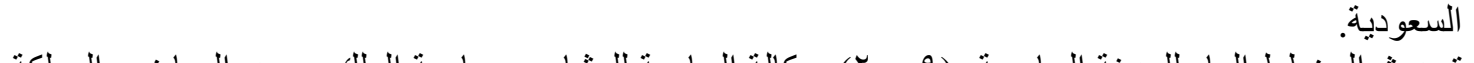

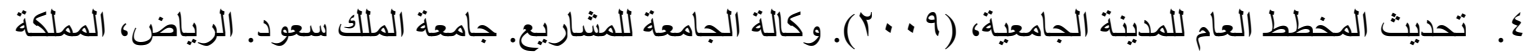
العربية السعودية.

5. Adewumi, A.; Joel, L.; and Sawyerr, B. (2014). Campus Parking Space Allocation Distribution Using Pattern Search and Particle Swarm Pattern Search Algorithms. SCIS\&ISIS: 196-203

6. Batabyal, A. and Nijkamp, P. (2010). A probabilistic analysis of two university parking issues. The Annals of Regional Science, 44 (1):111-120.

7. Brown, J., Hess, D.B., and Shoup, D. (2001) Unlimited access. Transportation 28 (3): 233-267

8. Box, P. C., (1992). Parking Systems and Loading Facilities. Transportation Planning Handbook (p. 175 - 200). Englewood cliffs, N.J.: Prentice hall

9. Ceder, A. (2015) Public Transit Planning and Operation: Modeling, Practice and Behavior, $2^{\text {nd }}$, CRC Press, Taylor \& Francis Group, London, UK

10. DCLG, Department for Communities and Local Government. (2011). Planning Policy Guidance 13: Transport. London, UK.

11. Maršanić, R., and Mrnjavac E., (2015), Role of parking in the hotel supply chain management. LogForum 11 (4), 387-397, DOI: 10.17270/J.LOG.2015.4.7

12. McShane, W., Roess, R., and Prassas, E. (2011). Traffic Engineering, $4^{\text {th }}$. PrenticeHall Inc.

13. Milosavljević, N.; Simićević J. 2018. Parking [In Serbian: Parkiranje]. University of Belgrade. Belgrade, Serbia.

Shunk, Gordon, A. (1992). Urban Transportation Systems. Transportation . I Planning Handbook (p. 88 - 122). Englewood cliffs, N.J.: Prentice hall .1 0

16. Weinberger, R.; Millard-Ball, A. and Hampshire, R. (2017). Parking Search Caused Congestion: Where's all the fuss? Transportation Research Board 96th Annual Meeting, Washington DC, United States, January (8-12).

17. Zhanlin, J.; Ganchev, I.; O'Droma, M.; Zhao, L. and Zhang, X. (2014). A Cloud-Based Car Parking Middleware for IoT-Based Smart Cities: Design and Implementation. Sensors, 14 (12), 22372-22393. 